\title{
Isobavachalcone Induces ROS-Mediated Apoptosis via Targeting Thioredoxin Reductase 1 in Human Prostate Cancer PC-3 Cells
}

\author{
Kai Li, ${ }^{1}$ Qiusheng Zheng $\mathbb{D}^{2}{ }^{2}$ Xiaoyu Chen, ${ }^{2}$ Yunchao Wang, ${ }^{1}$ Dan Wang, ${ }^{2}$ \\ and Jianning Wang $\mathbb{D}^{1}$ \\ ${ }^{1}$ Department of Urology, Shandong Provincial Qianfoshan Hospital, Shandong University, Jinan 250014, China \\ ${ }^{2}$ Binzhou Medical University, Yantai, Shandong 264003, China \\ Correspondence should be addressed to Jianning Wang; wjndoc@163.com
}

Received 15 January 2018; Revised 2 July 2018; Accepted 1 August 2018; Published 16 October 2018

Academic Editor: Kum Kum Khanna

Copyright ( $2018 \mathrm{Kai}$ Li et al. This is an open access article distributed under the Creative Commons Attribution License, which permits unrestricted use, distribution, and reproduction in any medium, provided the original work is properly cited.

\begin{abstract}
Prostate carcinoma causes a great number of deaths every year; therefore, there is an urgent need to find new drug candidates to treat advanced prostate cancer. Isobavachalcone (IBC) is the chalcone composition of Psoralea corylifolia Linn used in traditional Chinese medicine. Although IBC demonstrates potent anticancer efficacy in numerous types of human cancer cells, the cellular targets of IBC have not been fully defined. In our study, we found that IBC may induce reactive oxygen species(ROS-) mediated apoptosis via interaction with a selenocysteine ( $\mathrm{Sec}$ ) containing the antioxidant enzyme thioredoxin reductase 1 (TrxR1), and induce lethal endoplasmic reticulum (ER) stress by inhibiting TrxR1 activity and increasing ROS levels in human prostate cancer PC-3 cells. Furthermore, we also observed that knocking down TrxR1 would sensitized cancer cells to IBC treatment. Our study provides evidence for the anticancer mechanism of IBC with TrxR1 as a potential target.
\end{abstract}

\section{Introduction}

Prostate cancer leads to the second greatest number of cancer-related deaths following lung cancer. It is also the most frequent cancer diagnosis in men over 60 years of age and has a high incidence rate in younger men as well $[1,2]$. However, treatment options for prostate cancer are currently unsatisfactory, where the development of hormonal resistance is essentially inevitable and is the foremost cause of death in prostate cancer patients [3]. Therefore, it is urgent to accelerate the development of potential therapeutic agents to treat hormone refractory prostate cancers. Compounding this, these tumors often become highly resistant to conventionally used cytotoxic agents. Chinese traditional herbal medicine has been used to treat a wide range of diseases, including cancer, for hundreds of years [4]. Many natural compounds kill cancer cells and have no or minimal effects on normal cells. Therefore, there is an urgent search for natural compounds with anticancer activities to treat prostate cancer.
The thioredoxin (Trx) system plays an important role in regulating the redox balance in cells, which is composed of thioredoxin reductase (TrxR), Trx, and nicotinamide adenine dinucleotide phosphate (NADPH) [5-7]. TrxR is the only known enzyme capable of degrading thioredoxin, the inhibition of whose activity may destroy the redox function of some cells and lead to an increase in reactive oxygen species [8]. Oxidative stress is an important regulator of the behavior of cancer cells. While proper physiological reactive oxygen species (ROS) levels are necessary to maintain a number of cellular functions, ROS overproduction can overwhelm available intracellular antioxidants. This can disrupt the prooxidant/antioxidant balance, which can lead to cell damage and death $[9,10]$. A series of proapoptotic signaling pathways can also be triggered by overproduction of ROS, including those involved in mitochondrial dysfunction and endoplasmic reticulum (ER) stress, which can eventually result in apoptosis [11]. Malignant cells experience more oxidative stress than normal cells, rendering them vulnerable to oxidative stress $[12,13]$. Increasing evidence indicates that 
increasing oxidative stress may be a means of effectively eliminating cancer cells. Notably, prostate cancer cells have been demonstrated to have increased ROS production and oxidative stress [14]. Therefore, ROS-inducing agents may effectively kill prostate cancer cells.

Abnormal accumulation of unfolded/misfolded proteins or abrupt changes in $\mathrm{ER} \mathrm{Ca}^{2+}$ homeostasis causes an adaptive response in cells referred to as ER stress. However, excessive ER stress is closely associated with mitochondrial dysfunction and oxidative stress, and can result in apoptotic cell death [15-17]. Therefore, therapeutic modulation of proapoptotic ER stress is a possible means of chemosensitizing hormone refractory prostate cancer cells $[18,19]$.

Isobavachalcone (IBC) is a chalcone with multiple activities, including antifungal, anti-inflammatory, and antireverse transcriptase [20]. Prior work on a series of tumor and normal cells, including human umbilical vein endothelial and liver cells and the human hepatocyte LO2 line, has demonstrated that IBC has a notable toxicity on tumor cells but not normal cells [21]. This suggests that IBC treatment may be effective and have low toxicity in cancer patients. Reports have been published focusing on the anticancer abilities of IBC in certain types of tumors. However, how IBC affects human prostate cancer and the mechanisms behind these effects have yet to be fully delineated. The present study uses PC-3, a human androgen-independent prostate cancer cell line, to study the inhibition of proliferation by IBC in vitro, as well as the mechanisms mediating this inhibition. Overall, this work aims at providing theoretical and experimental evidence for furthering development of a candidate small molecule compound for targeted therapy against androgen-independent prostate cancer.

\section{Materials and Methods}

2.1. Chemicals and Reagents. IBC (purity $\geq 98 \%$ ) was obtained from Lichen Biotechnology Co. Ltd. (Shanghai, China). Dimethylsulfoxide (DMSO), buthionine sulfoximine (BSO), N-acetylcysteine (NAC), annexin V/PI apoptosis kit, Hoechst 33258, and $2^{\prime}, 7^{\prime}$-dichlorofluorescein diacetate (DCFH-DA) were purchased from Sigma-Aldrich (St. Louis, MO, USA). Streptomycin and penicillin were purchased from Sunrise Pharmaceutical Co. Ltd. (Shandong, China). IBC was initially dissolved in DMSO to obtain a stock solution and then diluted in RPMI 1640 to obtain a working solution with a final DMSO concentration of less than $0.1 \%$, which does not adversely affect cell viability. Any other reagents were purchased from Sigma Chemical Company (St. Louis, Missouri, USA).

2.2. Cells and Cell Culture. The human prostate cancer PC-3 cell line was purchased from the ATCC. Cells were cultured in RPMI 1640 containing 10\% FBS, $100 \mathrm{U} / \mathrm{mL}$ penicillin, and $100 \mu \mathrm{g} / \mathrm{mL}$ streptomycin in a humidified incubator with $5 \% \mathrm{CO}_{2}$ at $37^{\circ} \mathrm{C}$.

2.3. Treatments with Drugs. Immediately before each experiment, the IBC stock solution was diluted in culture media. IBC working solutions had a DMSO concentration of less than $0.1 \%$, and RPMI 1640 containing an equal concentration of DMSO as the IBC working solution was used as the control. In the first part of this study, PC-3 cells were treated with 15,30 , or $45 \mu \mathrm{M}$ IBC. In the second part of this study, PC-3 cells were treated with $45 \mu \mathrm{M}$ IBC in the absence or presence of $5 \mathrm{mM} \mathrm{NAC}$ and $1 \mathrm{mM}$ BSO. Following treatment, cells were harvested for further analysis.

2.4. Cell Viability. Cell viability was measured using the MTT assay. First, 96-well plates were seeded with PC-3 cells at a density of $0.7 \times 10^{4}$ cells per well and incubated for $24 \mathrm{~h}$ at $37^{\circ} \mathrm{C}$. These cells were then treated with IBC at different concentrations for 24,48 , or $72 \mathrm{~h}$. Then MTT $(5 \mathrm{mg} / \mathrm{mL})$ solution was added to each well and incubated for $4 \mathrm{~h}$. DMSO was added to each well $(150 \mu \mathrm{L} /$ well $)$ and the absorbance at $490 \mathrm{~nm}$ was measured using a microplate reader (Bio-Rad Laboratories, Hercules, CA, USA).

2.5. Morphology. To examine apoptosis of PC-3 cells, $2 \times 10^{5}$ cells per slide were seeded on 6-well chamber slides and treated with 15,30 , or $45 \mu \mathrm{M}$ IBC for $24 \mathrm{~h}$. An inverted phase contrast microscope was used to examine cell morphology and images were obtained using a 600D camera (Canon Inc., Japan). Cells were also fixed in $40 \mathrm{~g} / \mathrm{L}$ formaldehyde in PBS for $20 \mathrm{~min}$ and then stained with $10 \mathrm{mg} / \mathrm{L}$ Hoechst 33258 for $30 \mathrm{~min}$ in the dark. The stained cells were visualized using fluorescence microscopy [22].

2.6. Measurement of Apoptotic Population. Apoptosis was measured by staining cells with annexin V-FITC and PI. [23] Briefly, cells were incubated with IBC at a series of concentrations for different periods of time. Then, the cells were washed and stained with $5 \mu \mathrm{L}$ each of annexin V-FITC and PI for $10 \mathrm{~min}$, followed by analysis with flow cytometry (BD, NJ, USA).

2.7. Measurement of Intracellular ROS Levels. Intracellular ROS concentrations were quantified by flow cytometry as previously described [24]. Briefly, $3 \times 10^{5}$ cells were seeded in $60 \mathrm{~mm}$ dishes, incubated overnight, and then treated with reagents for different periods of time. Then, $10 \mu \mathrm{M}$ DCFHDA (Beyotime Institute of Biotechnolgy, Nantong, China) was added to the cells and incubated at $37^{\circ} \mathrm{C}$ for $30 \mathrm{~min}$. The cells were then collected, washed, and the fluorescence evaluated using flow cytometry (BD, NJ, USA).

2.8. Quantitative Real-Time Polymerase Chain Reaction. Total RNA was purified from PC-3 cells using TRIzol Reagent (Invitrogen) and used as template for reverse transcription using the PrimeScript RT-PCR Kit (TaKaRa, China). The resulting cDNA was used in semiquantitative real-time PCR. $\beta$-Action was used as an endogenous reference. PCR primer sequences were as follows: human GRP78, forward 5'-ACTGTTACAATCAAGGTCTATGAA GG-3' and reverse $5^{\prime}$-CAAAGGTGACTTCAATCTGTGG-3'; human XBP-1, forward $5^{\prime}$-GCGCCTCACGCACCTG-3' and reverse $5^{\prime}$-GCTGCTACTCTGTTTTTCAGTTTCC- ${ }^{\prime}$; human ATF4, forward $5^{\prime}$-TGGCTGGCTGTGGATGG-3' and reverse 5'-TCCCGGAGAAGGCATCCT-3'; human CHOP, forward 
$5^{\prime}$-CAGAACCAGCAGAGGTCACA- $3^{\prime}$ and reverse $5^{\prime}$-GCTG TGCCACTTTCCTTTC- ${ }^{\prime}$; and human $\beta$-action, forward $5^{\prime}$-TCCTTCCTGGGCATGGAGTC- $3^{\prime}$ and reverse $5^{\prime}$-GT AACGCAACTAAGTCATAGTC- $3^{\prime}$.

2.9. Western Blot. Cells $\left(1.0 \times 10^{5}\right.$ cells $\left./ \mathrm{mL}\right)$ were treated with IBC $(15,30$, or $45 \mu \mathrm{M})$ for $24 \mathrm{~h}$. After homogenization in protein lysate buffer, cells were centrifuged at $12,000 \mathrm{rpm}$ at $4^{\circ} \mathrm{C}$ for $10 \mathrm{~min}$. Protein concentrations of samples were measured and loading buffer was added to the protein samples, which were then electrophoresed and transferred to polyvinylidene difluoride transfer membranes. After blocking with fresh 5\% nonfat milk in TBST for $2 \mathrm{~h}$ at room temperature, the blots were incubated with primary antibody diluted in TBST at $4^{\circ} \mathrm{C}$ overnight. The blots were washed three times with TBST and then incubated with horseradish peroxidase-conjugated secondary antibody for $1 \mathrm{~h}$. Immunoreactive bands were visualized using an ECL kit (Bio-Rad Laboratories, Hercules, CA, USA) and the density of these bands was determined using Image $J$ software (National Institute of Health, MD).

2.10. In Vitro TrxR Activity Assays. A microplate reader (SpectraMax M5, Molecular Devices, USA) was used to determine TrxR activity by DTNB assay at room temperature. The incubation of NADPH-reduced TrxR $(150 \mathrm{nM})$ was achieved with IBC of different concentrations for two hours at room temperature (with the eventual volume of the reaction mixture as $50 \mu \mathrm{L}$ ) on a 96-well plate. The master mixture of TE buffer (50 mM Tris-HCl, pH 7.5, $1 \mathrm{mM}$ EDTA, $50 \mu \mathrm{L}$ ) containing DTNB and NADPH (final concentrations: $2 \mathrm{mM}$ and $200 \mu \mathrm{M}$, respectively) was added. The record of linear addition in absorbance at $412 \mathrm{~nm}$ during the first four minutes was performed. The equal amount of DMSO $(1 \%, v / v)$ was added in the control experiments with the activity denoted as percentage of the subjects in the control experiments.

2.11. Determination of TrxR Activity in Cells. After the treatment of cells with IBC with different concentrations for two hours, the harvesting and extraction of cells were achieved with RIPA buffer. The Bradford protein assay kit (Bio-Rad Laboratories, Hercules, CA, USA) was applied to determine the content of total protein. Based on an insulin decrease assay at the end points, the measurement of TrxR activity in cell lysates was achieved. Soon, incubation of cell extract was achieved and the eventual reaction volume was $50 \mu \mathrm{L}$, containing $100 \mathrm{mM}$ Tris- $\mathrm{HCl}$ (pH 7.6), $0.3 \mathrm{mM}$ insulin, $660 \mu \mathrm{M}$ NADPH, $3 \mathrm{mM}$ EDTA, and $15 \mu \mathrm{M}$ E. coli Trx (Sigma-Aldrich, St. Louis, MO), for a duration of $30 \mathrm{~min}$ at $37^{\circ} \mathrm{C}$. A total of $40 \mu \mathrm{g}$ of protein were contained in the extract. Through the addition of $200 \mu \mathrm{L}$ of $1 \mathrm{mM}$ DTNB in $6 \mathrm{M}$ guanidine hydrochloride ( $\mathrm{pH} 8.0$ ), the termination of the reaction was achieved. A blank sample, containing everything except Trx, was treated in the same manner.

The measurement of absorbance at $412 \mathrm{~nm}$ was carried out, followed by the subtraction of the blank value from the absorbance value of the sample accordingly. The activity was denoted as the percentage of the subject in the control group.

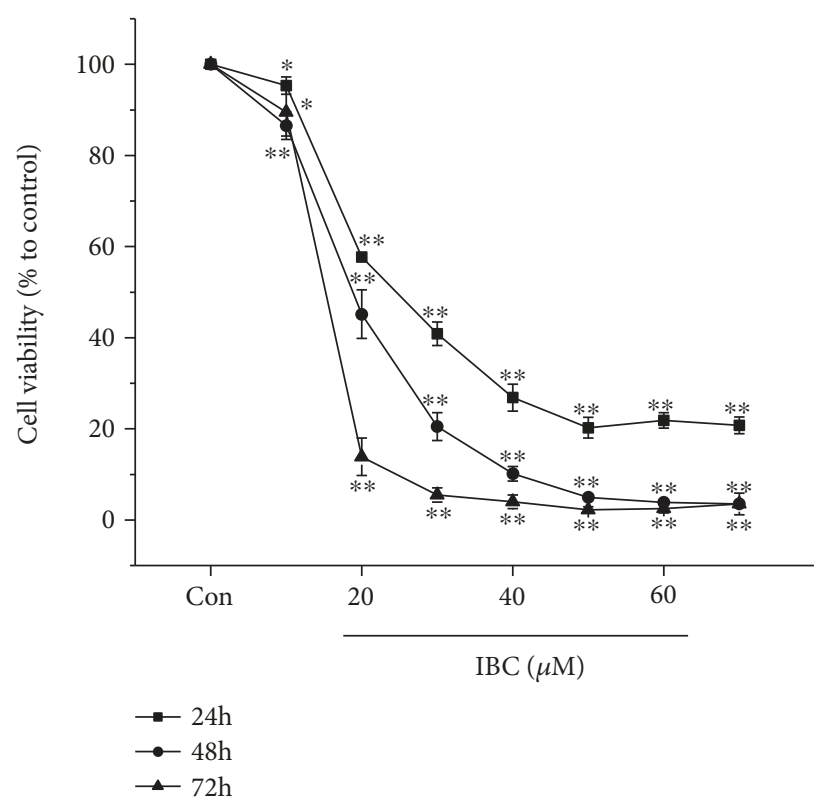

FIgURE 1: Effect of IBC on the proliferation of PC-3 cells. After treatment with IBC at a series of concentrations for 24,48 , or $72 \mathrm{~h}$, the viability of PC-3 cells was assessed with an MTT assay. All the data are expressed as percent change compared to the control group, which was arbitrarily designated as having $100 \%$ viability. All data are mean \pm S.D. ${ }^{*} p<0.05$ and ${ }^{* *} p<0.01$ compared to the control group.

2.12. Transient Transfection of Small Interfering RNA (siRNA). Small interfering RNA molecules, specifically targeting the TrxR1 mRNA, were obtained from SigmaAldrich (St. Louis, MO). For phenotypic confirmation, the following sequence was used: sense $5^{\prime}$-(CUUUGC AGCUGCGCUCAAA)dTdT- ${ }^{\prime}$, antisense $5^{\prime}$-(UUUGAG CGCAGCUGCAAAG)dTdT- $3^{\prime}$. The siRNA duplexes targeting TrxR1 were transduced into PC-3 cells. Forty-eight hours after transduction, cells were washed with complete media and seeded on 6-well plates. After treatment with IBC for $12 \mathrm{~h}$ or $24 \mathrm{~h}$, cells were harvested for immunoblot $(12 \mathrm{~h})$ or apoptosis $(24 \mathrm{~h})$ analysis.

2.13. Statistical Analysis. Results from at least three independent experiments are presented as mean \pm S.D. Statistical significance was determined using analysis of variance followed by Student's $t$-test. A $p$ value of $<0.05$ was considered statistically significant. All statistical analyses were performed using GraphPad Prism Pro 6.0 (GraphPad, San Diego, CA).

\section{Results}

3.1. IBC Inhibits Proliferation of PC-3 Cells. PC-3 cells were cultured with $0-70 \mu \mathrm{M}$ IBC for 24,48 , or $72 \mathrm{~h}$, followed by analysis with methyl thiazolyl tetrazolium (MTT) assay. The results showed that IBC can time- and concentrationdependently inhibit the proliferation of PC-3 cells (Figure 1). The $50 \%$ inhibitory concentrations (IC50s) of IBC in PC-3 cells for treatment for 24,48 , and $72 \mathrm{~h}$ were approximately $26.19,19.25$, and $14.80 \mu \mathrm{M}$, respectively. 

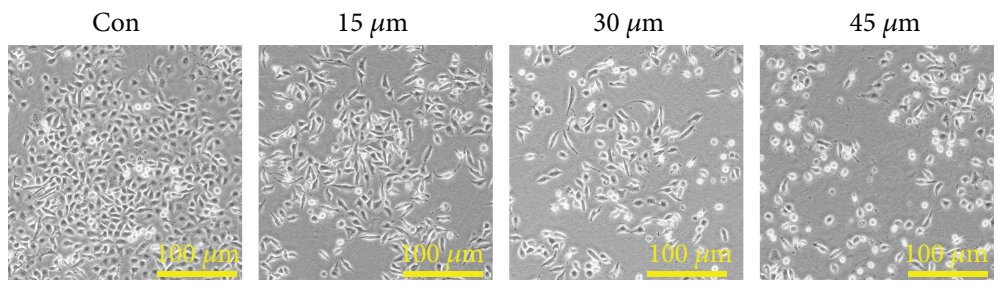

(a)
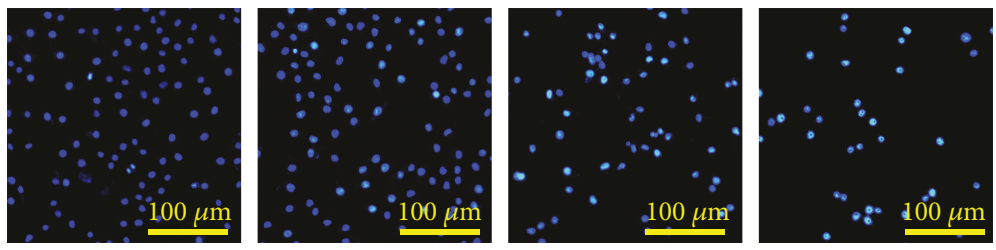

(b)
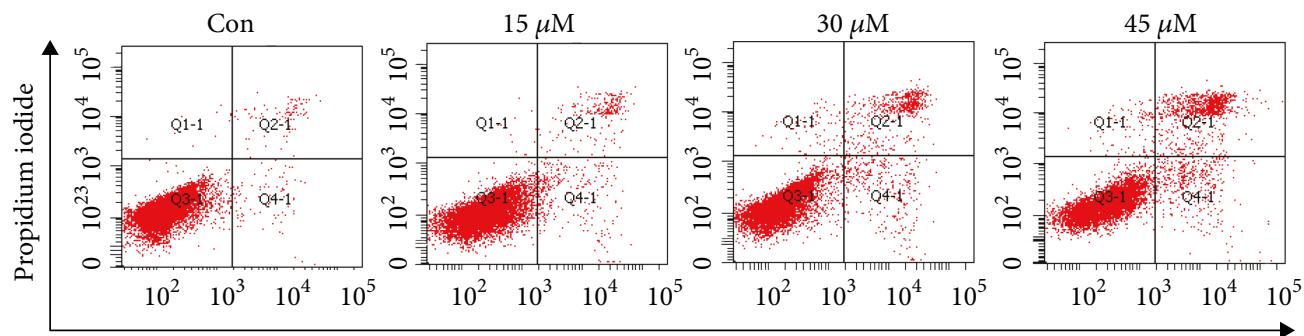

Annexin V-FITC

(c)

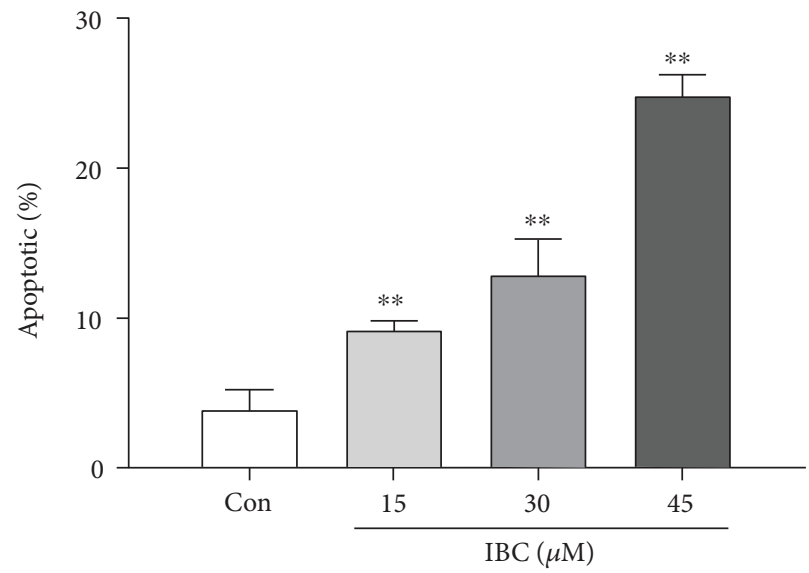

(d)

FIgure 2: Effect of IBC treatment on PC-3 cell morphology and apoptosis. Cells were exposed to 15, 30, or $45 \mu \mathrm{M}$ IBC for $24 \mathrm{~h}$. (a) After treating cells for $24 \mathrm{~h}$, the morphology of PC-3 cells was visualized and imaged by inverted phase contrast microscopy. (b) The morphological changes in PC-3 cells were examined following staining with Hoechst dye 33258. (c) Rate of apoptotic cells of IBC-treated PC-3 cells as detected by flow cytometry. (d) Quantitative analysis of the rate of apoptotic cells after IBC treatment. All data are presented as mean \pm S.D. ${ }^{*} p<0.05$ and ${ }^{* *} p<0.01$ compared with the control group.

3.2. IBC Induces Apoptosis of PC-3 Cells. Cells undergoing apoptosis characteristically present with cell shrinkage, membrane blebbing, nuclear condensation, and cleavage of chromatin. Therefore, apoptosis can be identified by light and electron microscopy based on the distinct apoptotic cell morphology [25]. Microscopic visualization of cell morphology revealed that IBC treatment caused notable cell shrinkage based on the scale bar and gaps between cells and reduced attachment of cells based on the cell number compared to the control group (Figure 2(a)).

Morphology was examined to quantify apoptosis using Hoechst dye staining. As shown in Figure 2(b), IBC-treated cells presented with apoptosis-associated characteristics, including small vesicles, cell shrinkage, chromatin compaction, cytoplasm condensation, and nuclear fragmentation, where the nuclei were smaller and more fluorescent than 


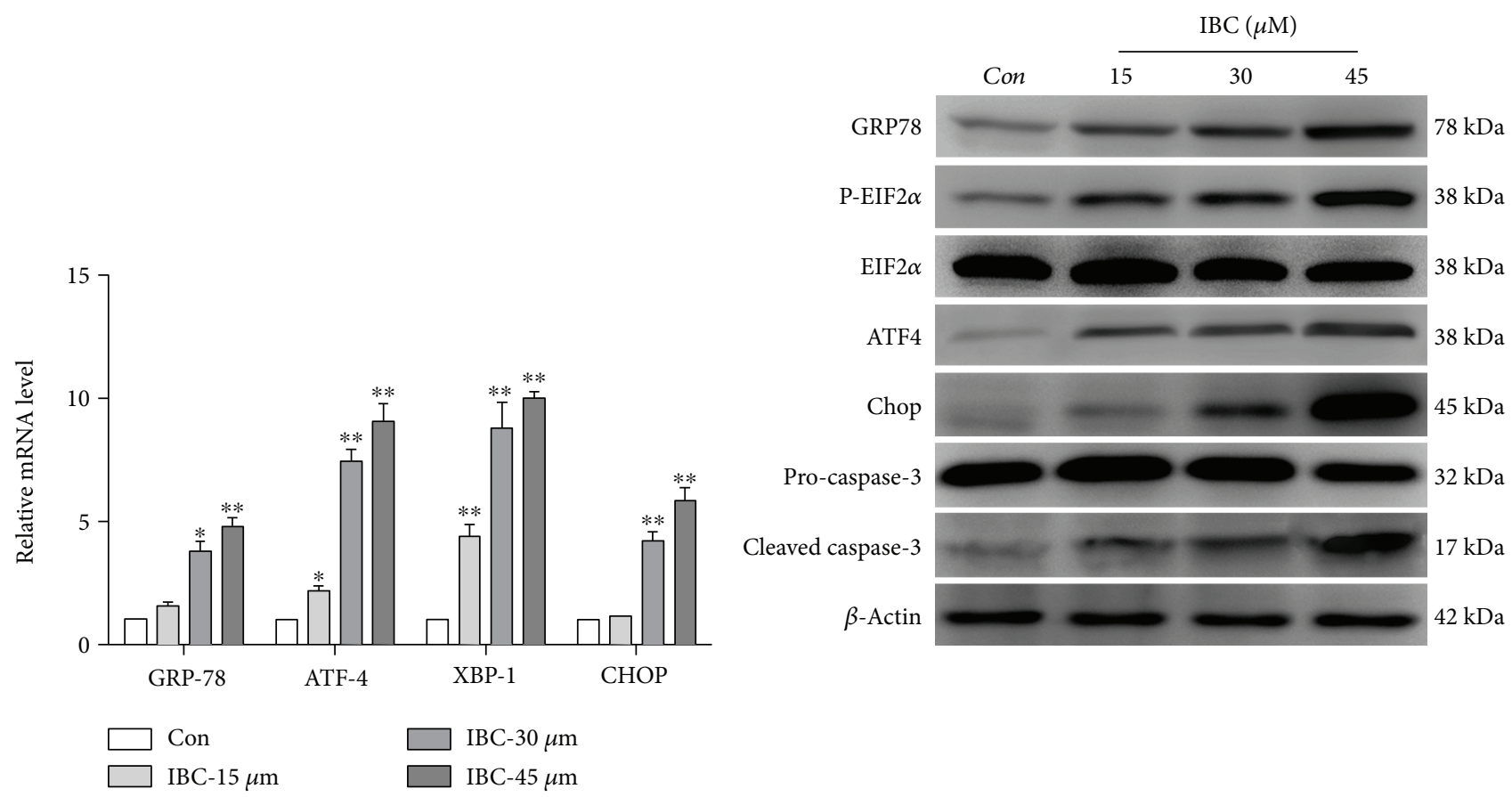

(a)

(b)

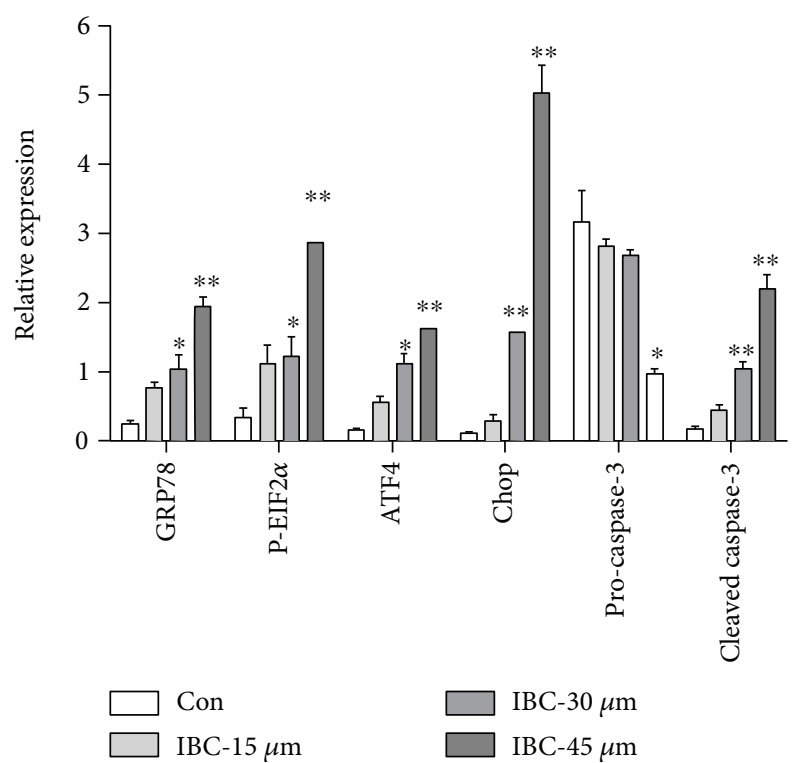

(c)

FIgURE 3: IBC activates ER stress, which contributes to the IBC-induced lethality of PC-3 cells. Cells were exposed to 15,30 , or $45 \mu \mathrm{M}$ IBC for 24h. (a) Quantitation of levels of GRP78, XBP-1, CHOP, and ATF4 mRNA by RT-qPCR. (b) Protein levels of GRP78, p-eIF2 $\alpha$, ATF4, Chop, eIF2 $\alpha$, pro-caspase-3, and cleaved caspase- 3 were determined by Western blot. (c) Quantitation of GRP78, p-eIF2 $\alpha$, eIF $2 \alpha$, ATF4, Chop, pro-caspase-3, and cleaved caspase-3 protein levels. All data are presented as mean \pm S.D. ${ }^{*} p<0.05$ and ${ }^{* *} p<0.01$ compared to the control group.

those in the control cells. Meanwhile, phosphatidylserine externalization, which is a hallmark of early apoptosis, was assessed by double staining cells with PI and annexin VFITC. Using flow cytometry, it was found that IBC significantly increased the percent of apoptotic cells from 3.87\% in the control group to $24.8 \%$ in the $45 \mu \mathrm{M}$ IBC treatment group (Figures 2(c) and 2(d)).
3.3. Effects of IBC on ER Stress Signaling and ApoptosisRelated Factors in PC-3 Cells. The next aim is to explore the mechanisms underlying the anticancer effects of IBC. Therefore, the effect of IBC treatment on the induction of ER stress was examined. RT-PCR revealed that treatment with IBC led to the upregulation of GRP78, ATF4, XBP-1, and Chop mRNA levels in PC-3 cells in a dose-dependent manner (Figure 3(a)). 
Next, the expression of a series of ER stress-related proteins including ATF4, GRP78, Chop, and p-eIF2 $\alpha$ was measured in PC-3 cells with or without IBC treatment. Results showed that IBC treatment induced a significant increase in protein expression levels. Specifically, p-eIF2 $\alpha$ levels peaked when treated with $15 \mu \mathrm{M}$ IBC (Figures 3(b) and 3(c)) and $45 \mu \mathrm{M}$ IBC significantly activated ER stress. In addition, expression levels of downstream effectors in apoptosis were measured. As shown in Figure 3(b), treating cells with IBC for $24 \mathrm{~h}$ activated caspase- 3 cleavage in a concentration-dependent manner, suggesting that apoptosis of PC-3 cells induced by IBC may be associated with the activation of the caspase pathway. This evidence demonstrates that IBC-induced apoptosis of PC-3 cells is mediated at least partially by the ER stress pathway.

3.4. IBC Directly Binds and Inactivates TrxR1 in PC-3 Cells. At present, TrxR has been considered as an important target molecule for the development of anticancer drugs [26]. Among the known TrxR inhibitors, the most common is the compound with a Michael addition receptor, which can be covalently bonded with the TrxR carbon-end Sec to reduce its activity [8,27-29]. Isobavachalcone contains a $\alpha, \beta$-unsaturated ketone structural unit, which is likely to inhibit TrxR activity by having a covalent additive reaction with the TrxR. When the TrxR is suppressed to lose its antioxidant function, the level of ROS in the cell increased and the intracellular redox balance was broken, resulting in oxidative stress.

As shown in Figure 4(a), IBC can inhibit the enzyme catalytic activity of the TrxR1 protein in a concentrationdependent manner, whether to the cell lysate or directly to the recombinant TrxR1 protein. The above results show that IBC can inhibit the activity of the TrxR1 protein, but whether TrxR1 mediates the activity of IBC against prostate cancer PC-3 cells needs further verification. Therefore, the following test examined the effect of TrxR1 silence on IBC-induced apoptosis of prostate cancer cells. As shown in Figure 4(b), the constructed TrxR1-specific siRNA can significantly silence the expression of the TrxR1 protein. Further research shows that TrxR1 silence can increase IBC-induced ROS level (Figure 4(c)) and apoptosis of prostate cancer cells (Figure 4(d)), indicating that TrxR1 participates in IBC's anti-prostate cancer effect.

3.5. Apoptosis of PC-3 Is Mediated by IBC-Induced ROS Overproduction. Accumulating evidence suggests that certain therapeutic agents trigger ROS production and this ROS production contributes to their mechanisms of cytotoxicity [30-32]. However, there have been few reports on IBCinduced ROS generation and oxidative stress. Therefore, generation of intracellular ROS with or without IBC treatment was measured by flow cytometry. Figures $5(\mathrm{a})$ and $5(\mathrm{~b})$ show that IBC $(45 \mu \mathrm{M})$ time- and concentration-dependently induced a significant increase in intracellular ROS in PC-3 cells. To elucidate the role of ROS in the anticancer effects of IBC, cells were treated with $5 \mathrm{mM}$ of antioxidant NAC and $1 \mathrm{mM}$ of the prooxidant buthionine sulfoximine (BSO) for $2 \mathrm{~h}$ prior to treatment with IBC, which did not significantly affect basal levels of cellular proliferation. ROS levels decreased in cells cotreated with NAC and IBC and increased in cells cotreated with BSO and IBC (Figures 5(c) and 5(d)). Similar results were noted in assays assessing apoptosis using flow cytometry (Figure 5(e)). Overall, these results confirm that IBC-induced apoptosis of PC-3 is mediated by ROS production.

3.6. IBC-Induced ER Stress in PC-3 Cells Is Mediated by ROS Generation. In this study, we discovered that ROS generation activated the proapoptotic signaling pathway, including the cell apoptosis pathway induced by ER stress [33, 34]. IBCinduced ROS generation occurs at a much earlier timepoint $(1 \mathrm{~h})$ than ER stress activation. Therefore, ROS production may occur upstream in IBC-induced cell death in PC-3 cells. Next, we characterized whether ROS production is necessary for IBC-induced ER stress in PC-3 cells. A combined treatment with NAC and IBC notably inhibited IBC-induced ER stress marker overexpression (Figures 6(a) and 6(b)). Conversely, cotreatment with BSO and IBC promoted IBCinduced ER stress marker expression. These results indicate that ER stress induced by treatment with IBC is mediated by increased oxidative stress.

\section{Discussion}

Prostate cancer is a leading cancer in men. Over the past two decades, the 5-year rate of survival has increased due to advancements in diagnostics for and treatment of prostate cancer [35]. However, even aggressive interventions, such as radiotherapy, chemotherapy, and surgery, do not guarantee that prostate cancer patients will be cured, especially those with castration-resistant prostate cancer [36]. Therefore, there is an urgent search for natural compounds with anticancer activities to treat prostate cancer. In this study, we demonstrated that IBC treatment caused apoptotic features, including increased ROS production in apoptotic cells, phosphatidylserine externalization in cell membranes, and caspase-3 activity, as well as a reduction in cell viability, in a concentration- and time-dependent manner. We next further characterize this inhibitory activity of IBC and explore the underlying mechanism in PC-3 cells.

Trx serves as an important target in cancer drug therapy. Trx and TrxR have been proved to be overexpressed in various cancer cells, and the rapid growth of their tumor cells are related to resistance to drugs [37]. Therefore, people are more and more interested in discovering new TrxR inhibitors as potential antitumor drugs [26, 34]. For the first time, we found that TrxR serves as the target of IBC in PC-3 cells, in which IBC can specifically target TrxR and induce apoptosis in PC-3 cells. The inhibiting TrxR stops the reduction of Trx and reduces the activity of various antioxidant enzyme systems that require reduction-state Trx as their electron donor. As a result, it causes the accumulation of ROS and changes the redox state within the cell [5]. The reduction-state Trx directly reacts with various enzymes related to apoptosis, such as ASK1 and pro-caspase-3 [38], and stops apoptosis. Therefore, the inhibition of TrxR strengthens apoptosis. The inhibition of TrxR will result in the generation of 


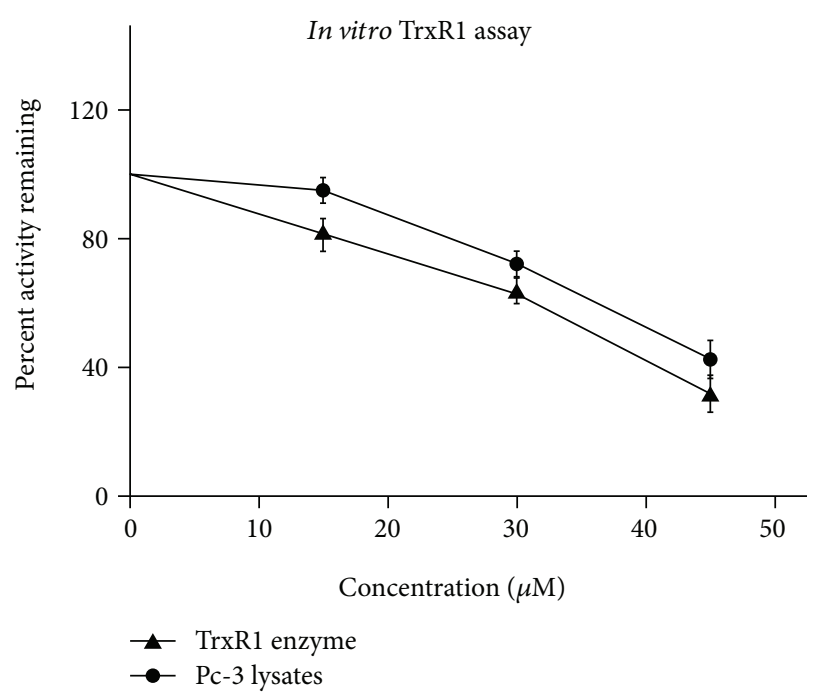

(a)

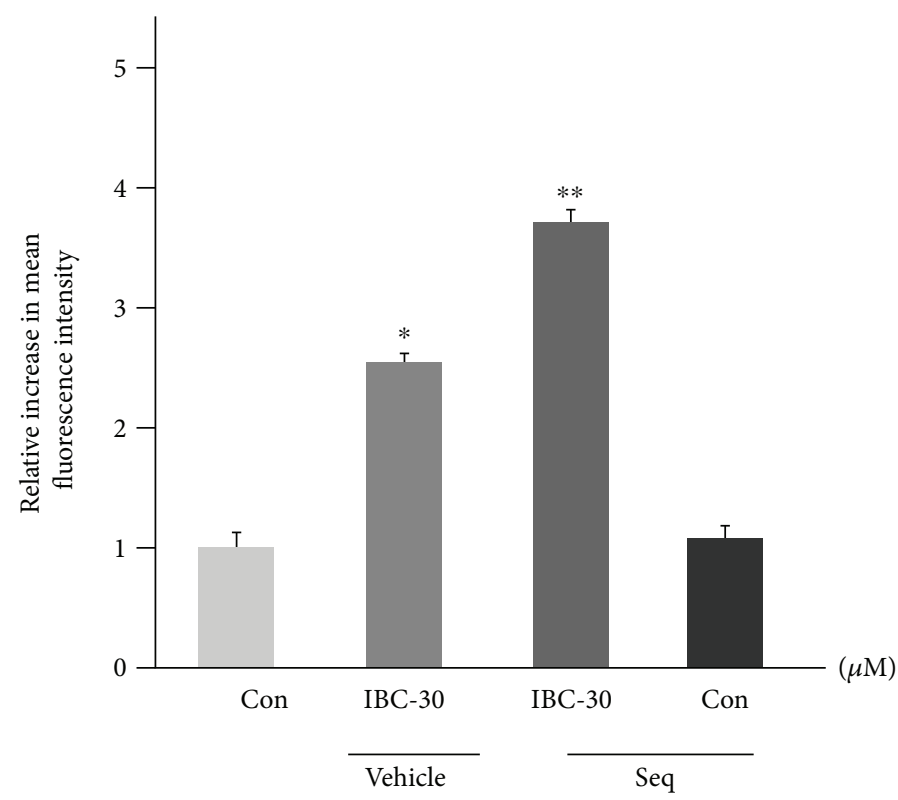

(c)
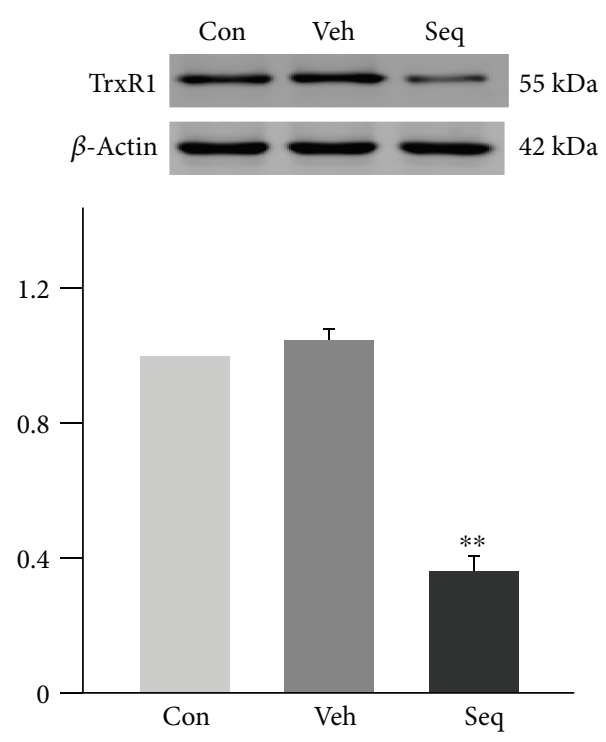

(b)

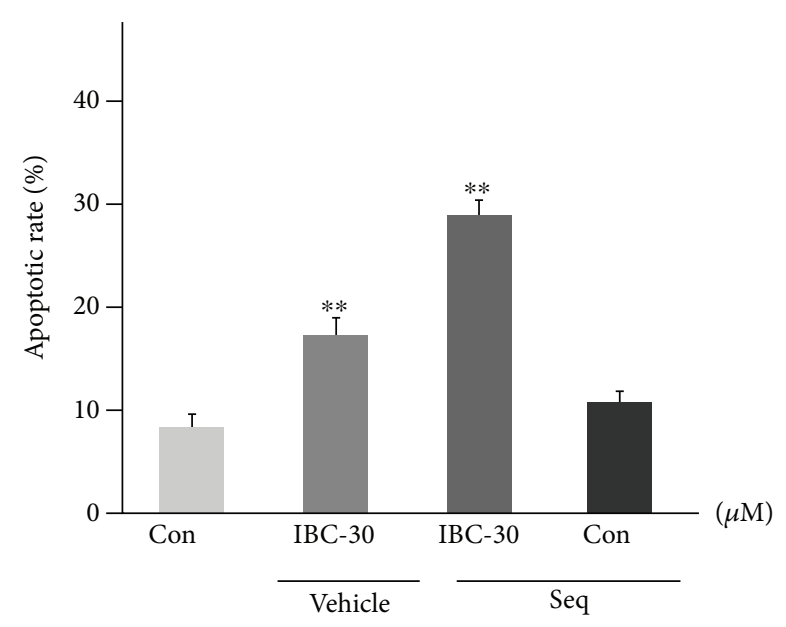

(d)

FIguRE 4: IBC directly binds and inactivates TrxR1 in PC-3 cells. (a) The activity of the TrxR1 enzyme. (b) The TrxR1 expression was determined by Western blotting after knockdown with siRNAs for $12 \mathrm{~h}$. (c) Knockdown of TrxR1 in PC-3 cells significantly increased the ROS levels (d) and apoptotic cells. All data are presented as mean \pm S.D. ${ }^{*} p<0.05$ and ${ }^{* *} p<0.01$ compared to the control group.

SecTRAPs (the Sec of its active site is replaced by an electrophile) [39]. These SecTRAPs have lost the ability to reduce Trx, and it will ultimately result in the rise of oxidative stress within the cell.

Intracellular ROS can cause oxidative stress, can disrupt the balance between prooxidants and antioxidants, and is a common response to cellular damage and death [40]. Results from this present study suggest that ROS has a critical role in IBC-induced ER stress in PC-3 cells. Firstly, ROS generation is concentration-dependently triggered by IBC. Second, ROS scavengers suppress ROS generation, while prooxidants promote ROS production. Third, cotreatment of PC- 3 cells with IBC and the ROS scavenger NAC caused a notable inhibition of IBC-induced ER stress marker overexpression, while cotreatment with IBC and the prooxidant BOS had the opposite effect. Overall, this suggests that ROS acts as a signal upstream in the initiation of IBC-induced ER stress. IBCinduced cytotoxicity and stimulation of ER stress in PC-3 

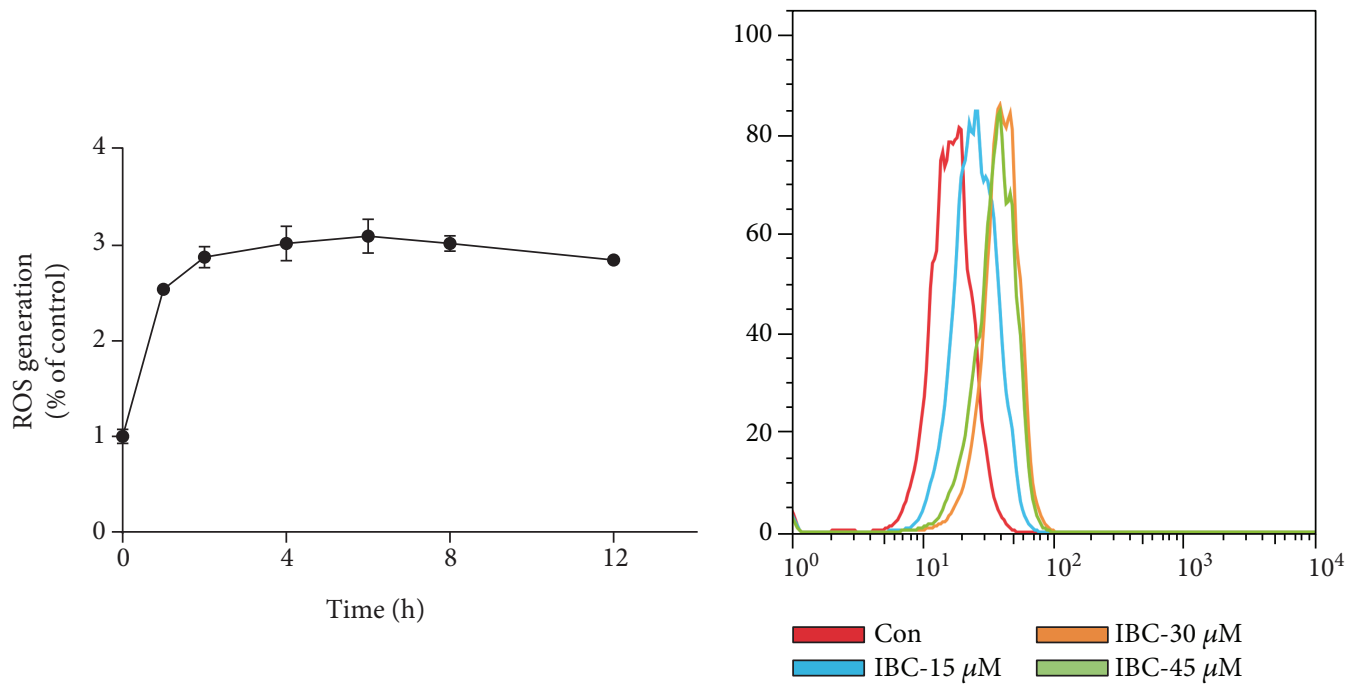

(a)

(b)
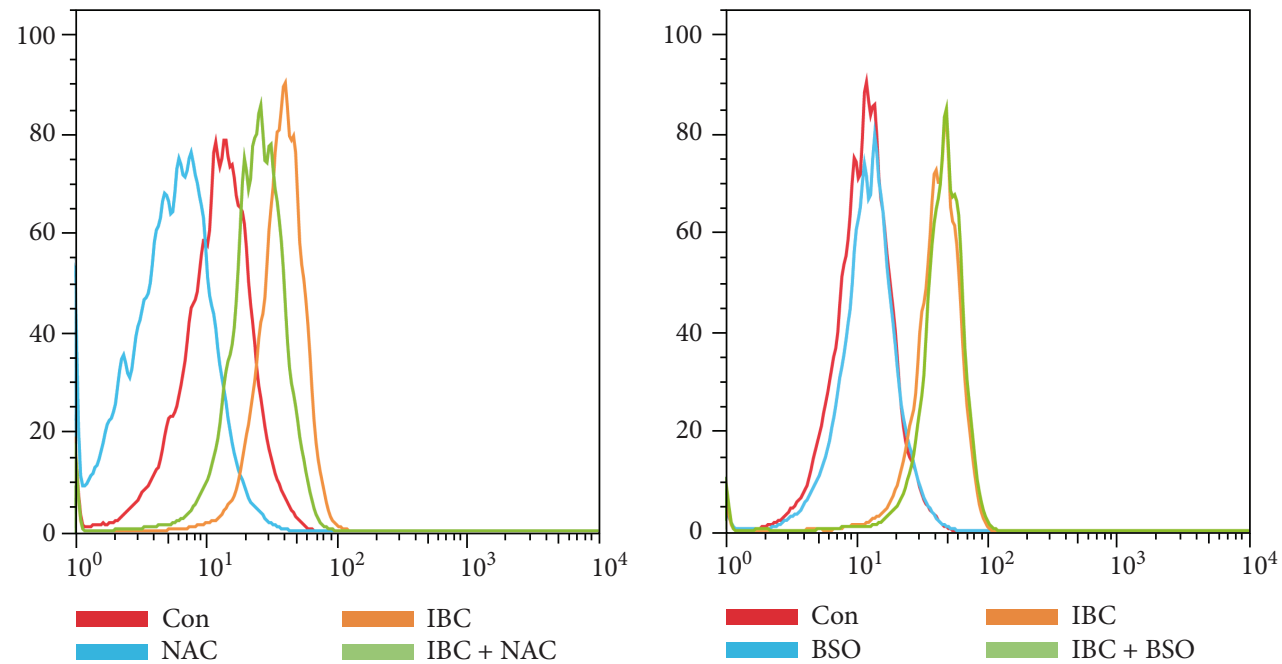

(c)

(d)
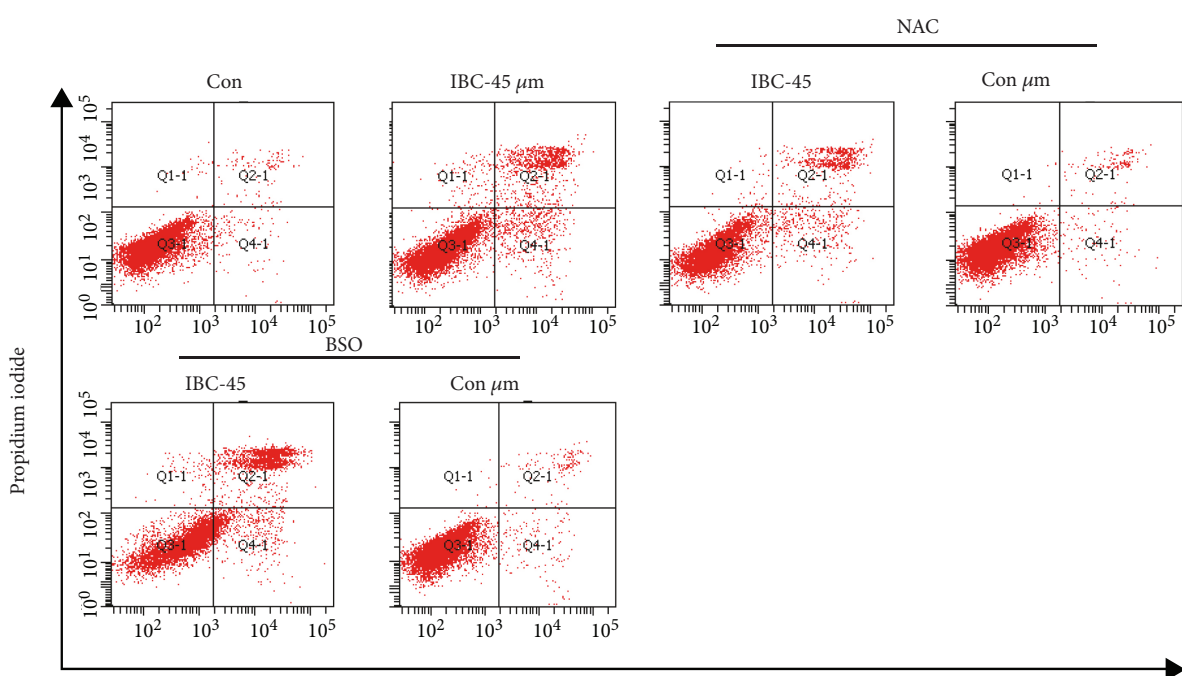

Annexin V-FITC

(e)

FIgURE 5: Continued. 

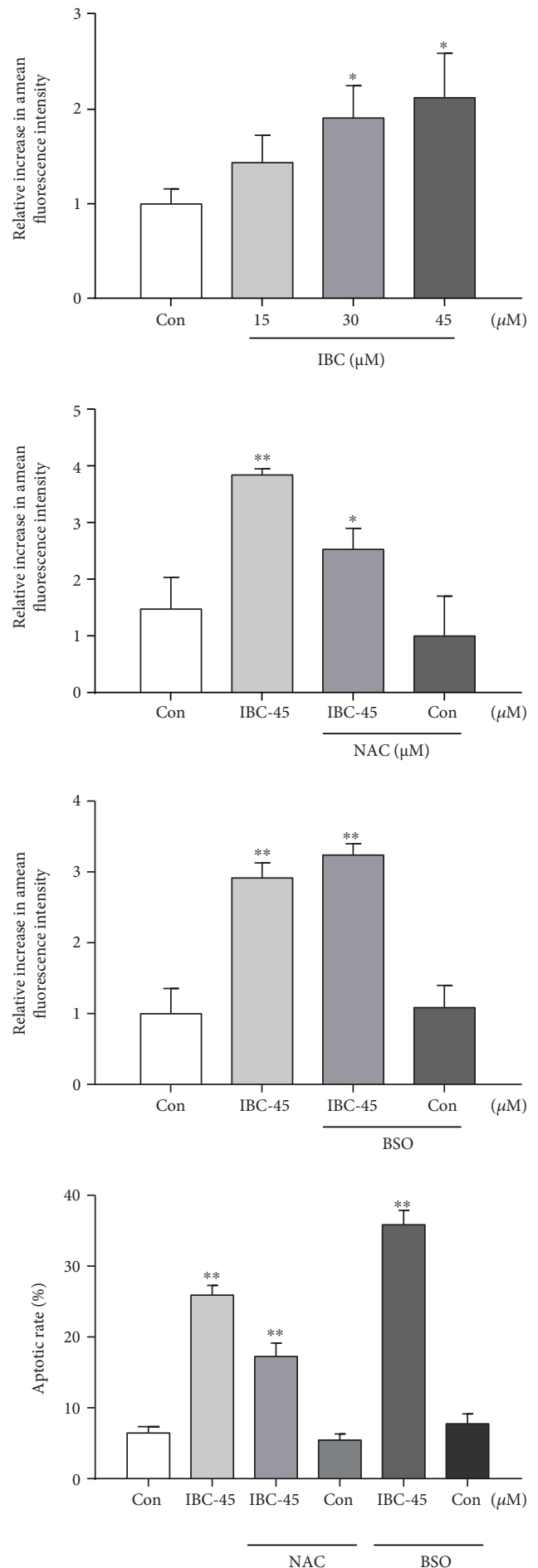

(f)

FIGURE 5: IBC-induced PC-3 cell apoptosis is dependent on intracellular ROS generation. (a) Time course of IBC-induced ROS production. As indicated, cells were treated for different lengths of time with $45 \mu \mathrm{M}$ IBC and then stained with $10 \mu \mathrm{M}$ DCFH-DA. The fluorescence intensity was measured by flow cytometry. (b) Intracellular IBC-induced ROS generation was measured by flow cytometry. (c-d) Representative images of ROS production in cells treated with IBC in the presence or absence of NAC or BOS. PC-3 cells were preincubated with NAC or BSO for $2 \mathrm{~h}$ before incubating with $45 \mu \mathrm{M}$ IBC for $6 \mathrm{~h}$. Intracellular ROS production was measured by flow cytometry. (e) Representative images of apoptotic cells identified by staining with annexin V-FITC/PI. Cells were treated with $45 \mu \mathrm{M}$ IBC in the presence or absence of NAC or BSO for $24 \mathrm{~h}$. Percentage of apoptotic cells was determined by annexin V/PI staining and flow cytometry. (f) Quantitative analysis of the rates of apoptotic PC-3 cells after IBC treatment. Data from three independent experiments are presented as mean \pm SD. ${ }^{*} p<0.05$ and ${ }^{* *} p<0.01$. 


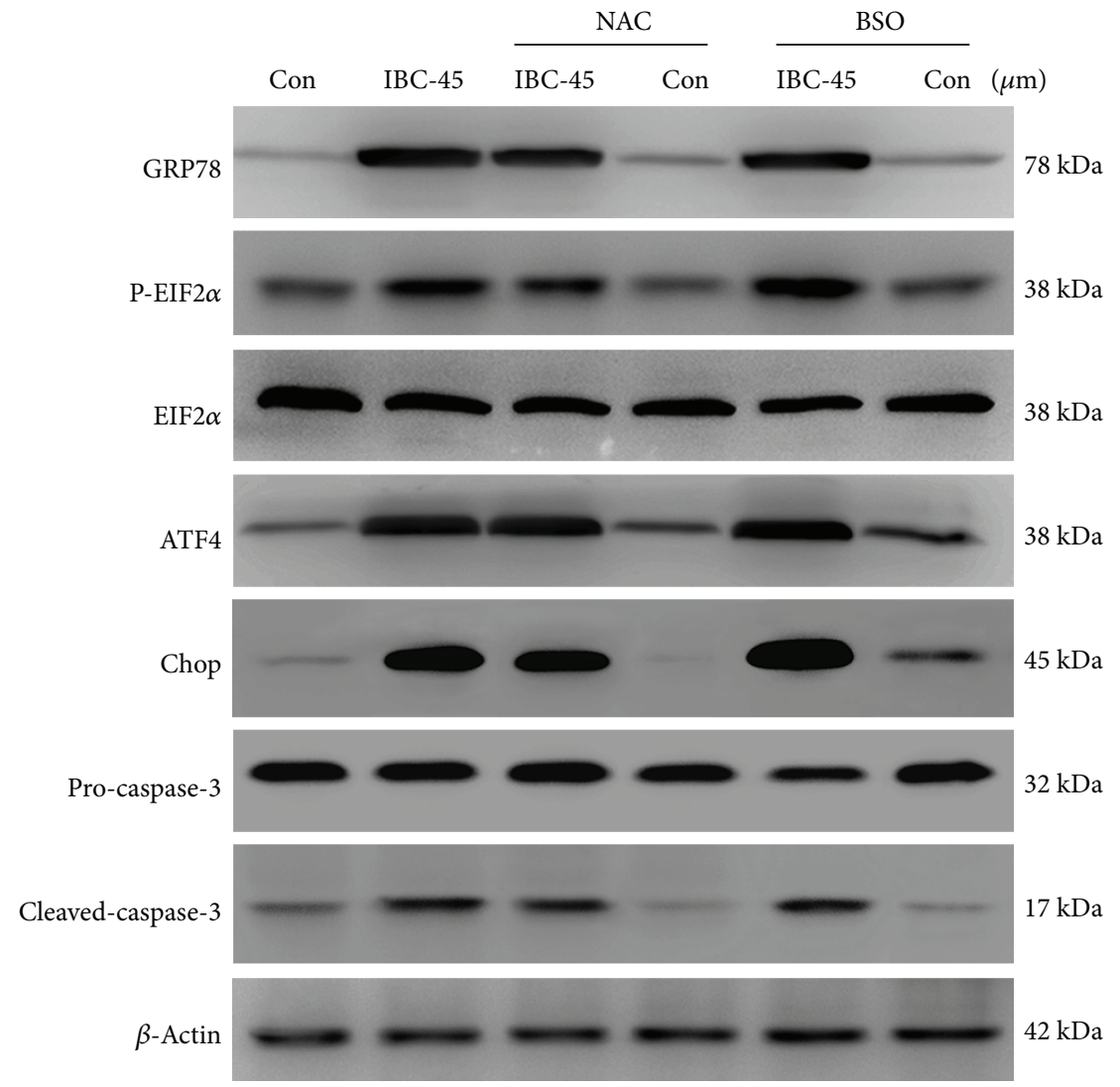

(a)

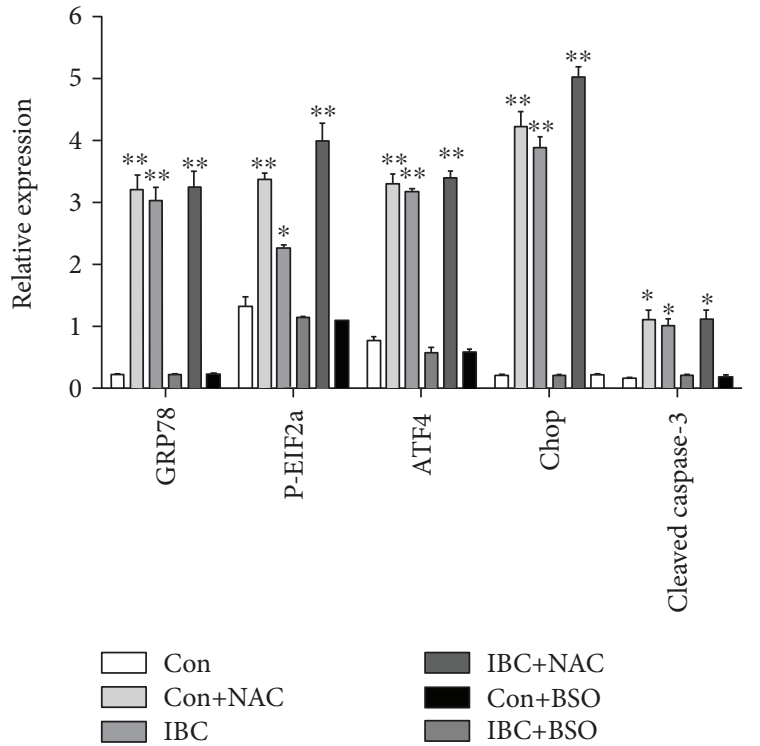

(b)

FIgURE 6: IBC-induced ER stress was mediated by ROS generation. PC-3 cells were treated with $45 \mu \mathrm{M}$ IBC with or without 5 mM NAC or $1 \mathrm{mM}$ BSO for $24 \mathrm{~h}$, and then ER stress marker expression levels were measured by Western blot. (a) Protein levels of GRP78, ATF4, Chop, and p-eIF $2 \alpha$ were examined by Western blot. (b) Quantitative analysis of GRP78, ATF4, Chop, and p-eIF2 $\alpha$ protein levels. All data are presented as mean \pm S.D. ${ }^{*} p<0.05$ and ${ }^{* *} p<0.01$ compared to the control group.

cells were decreased, but not completely inhibited, by NAC, which suggests that additional signaling molecules/pathways might contribute to IBC-dependent prostate cancer cell death. A previous work has demonstrated that mitochondrial signaling pathways are involved in the regulation of IBCinduced prostate cancer cell death [21]. 
The ER is a well-known regulator of cellular responses to stress. Specifically, a disturbance of ER homeostasis triggers the unfolded protein response. Misfolded proteins can accumulate in the ER, which causes ER stress and ultimately results in cell apoptosis [41]. Three major ER stress sensors help protect against the negative effects of ER stress by triggering the unfolded protein response, including ATF6, IRE-1/XBP-1, and PERK/eIF2 $\alpha$, which leads to a decrease in translation, degradation of misfolded proteins, and increased levels of chaperones in an effort to increase protein folding and degradation in the ER $[42,43]$. CHOP is a downstream player in ER stress and is a marker for cells committed to ER stress-induced apoptosis. CHOP is present at low levels under physiological conditions, but its expression is dramatically increased in response to ER stress at the transcriptional level via the XBP-1, ATF4, and ATF6 pathways [44, 45]. ER stressinduced apoptosis is an attractive signaling target in cancer cells when designing and developing cancer therapeutics. For example, ER stress-mediated apoptosis has been shown to be induced in cancer cells by certain anticancer agents, including EF24, Icariin, and arsenic trioxide [46, 47]. However, the role of ER stress-related apoptotic signals in IBCinduced prostate cancer cell death has yet to be delineated. In this present study, analysis by RT-PCR and Western blot revealed that exposing PC-3 cells to $45 \mu \mathrm{M}$ IBC significantly increased mRNA and protein expression levels, respectively, of GRP78, phosphorylated eIF $2 \alpha$, ATF- 4 , XBP- 1 , and CHOP. Collectively, the results of this study underscore the important role that ER stress plays in IBC-induced apoptosis of prostate cancer cells.

Apoptosis has been reported to be essential to the maintenance of cell and tissue homeostasis [48]. In this study, IBC was found to trigger apoptotic events, including phosphatidylserine externalization, chromatin condensation, and DNA fragmentation in PC-3 cells. Activation of caspase3 , the primary executioner caspase in the majority of systems, irreversibly commits a cell to apoptosis. Therefore, caspase-3 activation serves as a reliable marker of apoptotic cells [49]. IBC was found to significantly reduce pro-caspase-3 levels with a concurrent increase in cleaved caspase-3 levels in PC-3 cells. IBC showed high toxicity to PC-3 cells mainly because IBC induced apoptosis, thus enhancing the clinical application of IBC in the treatment of cancer.

\section{Conclusion}

In summary, we have discovered that IBC induces cell apoptosis through ROS-mediated ER stress by interaction with TrxR1. This provides a deep insight into the action mechanism of IBC, and also suggests that TrxR1 is a potential target for the development of anticancer agents.

\section{Data Availability}

The data used to support the findings of this study are available from the corresponding author upon request.

\section{Conflicts of Interest}

All authors have no conflicts of interests to declare.

\section{Authors' Contributions}

Kai Li and Qiusheng Zheng are co-first authors.

\section{Acknowledgments}

The work was supported by the Key Research Plan of Shangdong Province (2016GSF121027).

\section{References}

[1] R. Siegel, J. Ma, Z. Zou, and A. Jemal, "Cancer. Statistics, 2014,” CA: A Cancer Journal for Clinicians, vol. 64, no. 1, pp. 9-29, 2014.

[2] S. C. Williamson, A. E. Hartley, and R. Heer, "A review of tasquinimod in the treatment of advanced prostate cancer," Drug Design, Development and Therapy, vol. 7, pp. 167-174, 2013.

[3] T. M. S. Amaral, D. Macedo, I. Fernandes, and L. Costa, "Castration-resistant prostate cancer: mechanisms, targets, and treatment," Prostate Cancer, vol. 2012, Article ID 327253, 11 pages, 2012.

[4] N. H. Yim, A. Kim, Y. P. Jung, T. Kim, C. J. Ma, and J. Y. Ma, "Fermented So-Cheong-Ryong-Tang (FCY) induces apoptosis via the activation of caspases and the regulation of MAPK signaling pathways in cancer cells," BMC Complementary and Alternative Medicine, vol. 15, no. 1, p. 336, 2015.

[5] J. Lu and A. Holmgren, "The thioredoxin antioxidant system," Free Radical Biology \& Medicine, vol. 66, no. 8, pp. 75-87, 2014.

[6] A. Bindoli and M. P. Rigobello, "Principles in redox signaling: from chemistry to functional significance," Antioxidants \& Redox Signaling, vol. 18, no. 13, pp. 1557-1593, 2013.

[7] E. S. J. Arnér, "Focus on mammalian thioredoxin reductases-important selenoproteins with versatile functions," Biochimica et Biophysica Acta (BBA) - General Subjects, vol. 1790, no. 6, pp. 495-526, 2009.

[8] W. Cai, B. Zhang, D. Duan, J. Wu, and J. Fang, "Curcumin targeting the thioredoxin system elevates oxidative stress in HeLa cells," Toxicology and Applied Pharmacology, vol. 262, no. 3, pp. 341-348, 2012.

[9] M. Ott, V. Gogvadze, S. Orrenius, and B. Zhivotovsky, "Mitochondria, oxidative stress and cell death," Apoptosis, vol. 12, no. 5, pp. 913-922, 2007.

[10] S. W. Ryter, H. P. Kim, A. Hoetzel et al., "Mechanisms of cell death in oxidative stress," Antioxidants \& Redox Signaling, vol. 9, no. 1, pp. 49-89, 2007.

[11] M. L. Circu and T. Y. Aw, "Reactive oxygen species, cellular redox systems, and apoptosis," Free Radical Biology \& Medicine, vol. 48, no. 6, pp. 749-762, 2010.

[12] R. A. Cairns, I. S. Harris, and T. W. Mak, "Regulation of cancer cell metabolism," Nature Reviews Cancer, vol. 11, no. 2, pp. 85-95, 2011.

[13] D. Trachootham, J. Alexandre, and P. Huang, "Targeting cancer cells by ROS-mediated mechanisms: a radical therapeutic approach?," Nature Reviews Drug Discovery, vol. 8, no. 7, pp. 579-591, 2009. 
[14] X. Zhang, M. Chen, P. Zou et al., "Curcumin analog WZ35 induced cell death via ROS-dependent ER stress and G2/M cell cycle arrest in human prostate cancer cells," BMC Cancer, vol. 15, no. 1, p. 866, 2015.

[15] C. M. Haynes, E. A. Titus, and A. A. Cooper, "Degradation of misfolded proteins prevents ER-derived oxidative stress and cell death," Molecular Cell, vol. 15, no. 5, pp. 767-776, 2004.

[16] T. Momoi, "Caspases involved in ER stress-mediated cell death," Journal of Chemical Neuroanatomy, vol. 28, no. 1-2, pp. 101-105, 2004.

[17] T. C. Yeh, P. C. Chiang, T. K. Li et al., "Genistein induces apoptosis in human hepatocellular carcinomas via interaction of endoplasmic reticulum stress and mitochondrial insult," Biochemical Pharmacology, vol. 73, no. 6, pp. 782-792, 2007.

[18] K. S. Eom, H. J. Kim, H. S. So, R. Park, and T. Y. Kim, "Berberine-induced apoptosis in human glioblastoma T98G cells is mediated by endoplasmic reticulum stress accompanying reactive oxygen species and mitochondrial dysfunction," Biological \& Pharmaceutical Bulletin, vol. 33, no. 10, pp. 16441649, 2010.

[19] Y. Wu, M. Fabritius, and C. Ip, "Chemotherapeutic sensitization by endoplasmic reticulum stress: increasing the efficacy of taxane against prostate cancer," Cancer Biology \& Therapy, vol. 8, no. 2, pp. 146-152, 2009.

[20] T. Akihisa, H. Tokuda, D. Hasegawa et al., "Chalcones and other compounds from the exudates of Angelica keiskei and their cancer chemopreventive effects," Journal of Natural Products, vol. 69, no. 1, pp. 38-42, 2006.

[21] H. Jing, X. Zhou, X. Dong et al., “Abrogation of Akt signaling by isobavachalcone contributes to its anti-proliferative effects towards human cancer cells," Cancer Letters, vol. 294, no. 2, pp. 167-177, 2010.

[22] C. Wang, L. Jiang, S. Wang et al., "The antitumor activity of the novel compound Jesridonin on human esophageal carcinoma cells," PloS One, vol. 10, no. 6, article e0130284, 2015.

[23] H. Zhao, X. Yuan, D. Li et al., "Isoliquiritigen enhances the antitumour activity and decreases the genotoxic effect of cyclophosphamide," Molecules, vol. 18, no. 8, pp. 8786-8798, 2013.

[24] P. Zou, J. Zhang, Y. Xia et al., "ROS generation mediates the anti-cancer effects of WZ35 via activating JNK and ER stress apoptotic pathways in gastric cancer," Oncotarget, vol. 6, no. 8, pp. 5860-5876, 2015.

[25] G. Wang, C. Liu, J. Liu et al., "Exopolysaccharide from Trichoderma pseudokoningii induces the apoptosis of MCF-7 cells through an intrinsic mitochondrial pathway," Carbohydrate Polymers, vol. 136, pp. 1065-1073, 2016.

[26] E. S. J. Arnér, "Selenoproteins-what unique properties can arise with selenocysteine in place of cysteine?," Experimental Cell Research, vol. 316, no. 8, pp. 1296-1303, 2010.

[27] J. Zhang, Y. Li, D. Duan, J. Yao, K. Gao, and J. Fang, "Inhibition of thioredoxin reductase by alantolactone prompts oxidative stress-mediated apoptosis of HeLa cells," Biochemical Pharmacology, vol. 102, pp. 34-44, 2016.

[28] B. Zhang, D. Duan, C. Ge et al., "Synthesis of xanthohumol analogues and discovery of potent thioredoxin reductase inhibitor as potential anticancer agent," Journal of Medicinal Chemistry, vol. 58, no. 4, pp. 1795-1805, 2015.

[29] D. Duan, B. Zhang, J. Yao et al., "Gambogic acid induces apoptosis in hepatocellular carcinoma SMMC-7721 cells by targeting cytosolic thioredoxin reductase," Free Radical Biology \& Medicine, vol. 69, no. 4, pp. 15-25, 2014.
[30] D. Duan, B. Zhang, J. Yao, Y. Liu, and J. Fang, "Shikonin targets cytosolic thioredoxin reductase to induce ROS-mediated apoptosis in human promyelocytic leukemia HL-60 cells," Free Radical Biology \& Medicine, vol. 70, pp. 182-193, 2014.

[31] Y. Liu, D. Duan, J. Yao et al., "Dithiaarsanes induce oxidative stress-mediated apoptosis in HL-60 cells by selectively targeting thioredoxin reductase," Journal of Medicinal Chemistry, vol. 57, no. 12, pp. 5203-5211, 2014.

[32] L. Raj, T. Ide, A. U. Gurkar et al., "Selective killing of cancer cells by a small molecule targeting the stress response to ROS," Nature, vol. 475, no. 7355, pp. 231-234, 2011.

[33] P. Zou, M. Chen, J. Ji et al., "Auranofin induces apoptosis by ROS-mediated ER stress and mitochondrial dysfunction and displayed synergistic lethality with piperlongumine in gastric cancer," Oncotarget, vol. 6, no. 34, pp. 36505-36521, 2015.

[34] P. Zou, Y. Xia, W. Chen et al., "EF24 induces ROS-mediated apoptosis via targeting thioredoxin reductase 1 in gastric cancer cells," Oncotarget, vol. 7, no. 14, pp. 18050-18064, 2016.

[35] J. B. Aragon-Ching, "The evolution of prostate cancer therapy: targeting the androgen receptor," Frontiers in Oncology, vol. 4, 2014.

[36] S. Giacinti, M. Bassanelli, A. M. Aschelter, A. Milano, M. Roberto, and P. Marchetti, "Resistance to abiraterone in castration-resistant prostate cancer: a review of the literature," Anticancer Research, vol. 34, no. 11, pp. 6265-6269, 2014.

[37] S. Urig and K. Becker, "On the potential of thioredoxin reductase inhibitors for cancer therapy," Seminars in Cancer Biology, vol. 16, no. 6, pp. 452-465, 2006.

[38] D. A. Mitchell, S. U. Morton, N. B. Fernhoff, and M. A. Marletta, "Thioredoxin is required for S-nitrosation of procaspase-3 and the inhibition of apoptosis in Jurkat cells," Proceedings of the National Academy of Sciences of the United States of America, vol. 104, no. 28, pp. 11609-11614, 2007.

[39] K. Anestål, S. Prast-Nielsen, N. Cenas, and E. S. J. Arnér, “Cell death by SecTRAPs: thioredoxin reductase as a prooxidant killer of cellS," PloS One, vol. 3, no. 4, article e1846, 2008.

[40] S. V. Avery, "Molecular targets of oxidative stress," The Biochemical Journal, vol. 434, no. 2, pp. 201-210, 2011.

[41] H. Puthalakath, L. A. O'Reilly, P. Gunn et al., "ER stress triggers apoptosis by activating $\mathrm{BH} 3$-only protein Bim," Cell, vol. 129, no. 7, pp. 1337-1349, 2007.

[42] J. D. Malhotra and R. J. Kaufman, "The endoplasmic reticulum and the unfolded protein response," Seminars in Cell \& Developmental Biology, vol. 18, no. 6, pp. 716-731, 2007.

[43] D. Ron and P. Walter, "Signal integration in the endoplasmic reticulum unfolded protein response," Nature Reviews Molecular Cell Biology, vol. 8, no. 7, pp. 519-529, 2007.

[44] S. Oyadomari and M. Mori, "Roles of CHOP/GADD153 in endoplasmic reticulum stress," Cell Death and Differentiation, vol. 11, no. 4, pp. 381-389, 2004.

[45] S. M. Huang, C. W. Cheung, C. S. Chang et al., "Phloroglucinol derivative MCPP induces cell apoptosis in human colon cancer," Journal of Cellular Biochemistry, vol. 112, no. 2, pp. 643-652, 2011.

[46] C. Fan, Y. Yang, Y. Liu et al., "Icariin displays anticancer activity against human esophageal cancer cells via regulating endoplasmic reticulum stress-mediated apoptotic signaling," Scientific Reports, vol. 6, no. 1, 2016.

[47] X. Y. Zhang, S. M. Yang, H. P. Zhang et al., "Endoplasmic reticulum stress mediates the arsenic trioxide-induced apoptosis in human hepatocellular carcinoma cells," The 
International Journal of Biochemistry \& Cell Biology, vol. 68, pp. 158-165, 2015.

[48] L. Yu, J. Ma, J. Han et al., "Licochalcone B arrests cell cycle progression and induces apoptosis in human breast cancer MCF-7 cells," Recent Patents on Anti-Cancer Drug Discovery, vol. 11, no. 4, pp. 444-452, 2016.

[49] S. W. G. Tait and D. R. Green, "Mitochondria and cell death: outer membrane permeabilization and beyond," Nature Reviews Molecular Cell Biology, vol. 11, no. 9, pp. 621-632, 2010. 


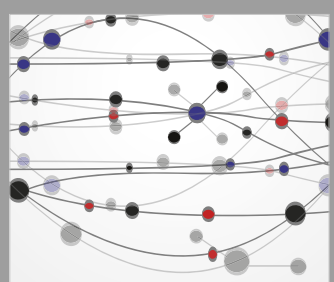

The Scientific World Journal
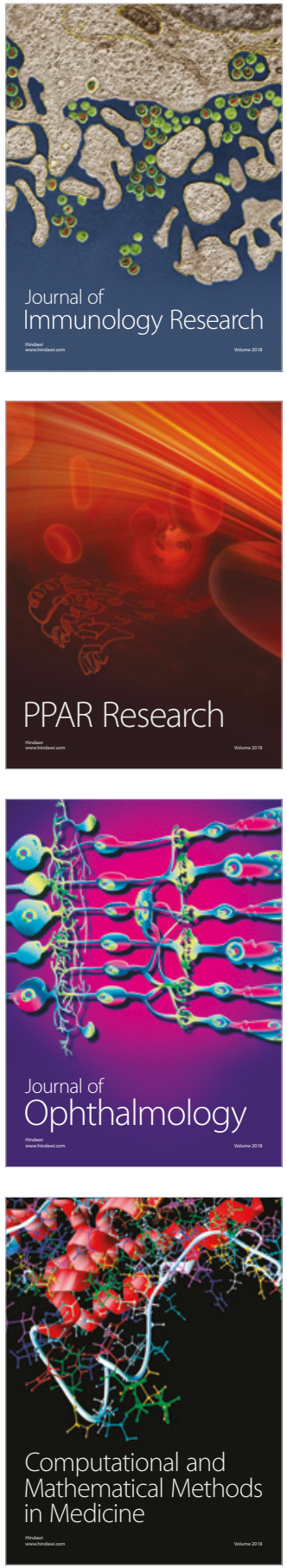

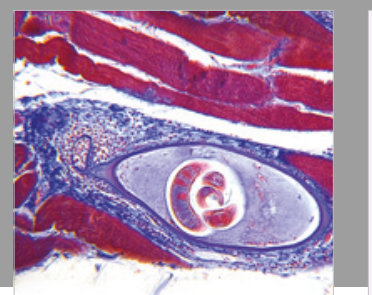

Gastroenterology Research and Practice

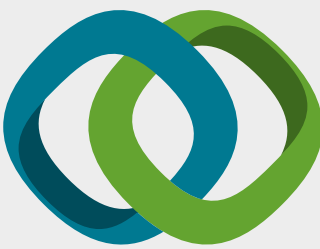

\section{Hindawi}

Submit your manuscripts at

www.hindawi.com
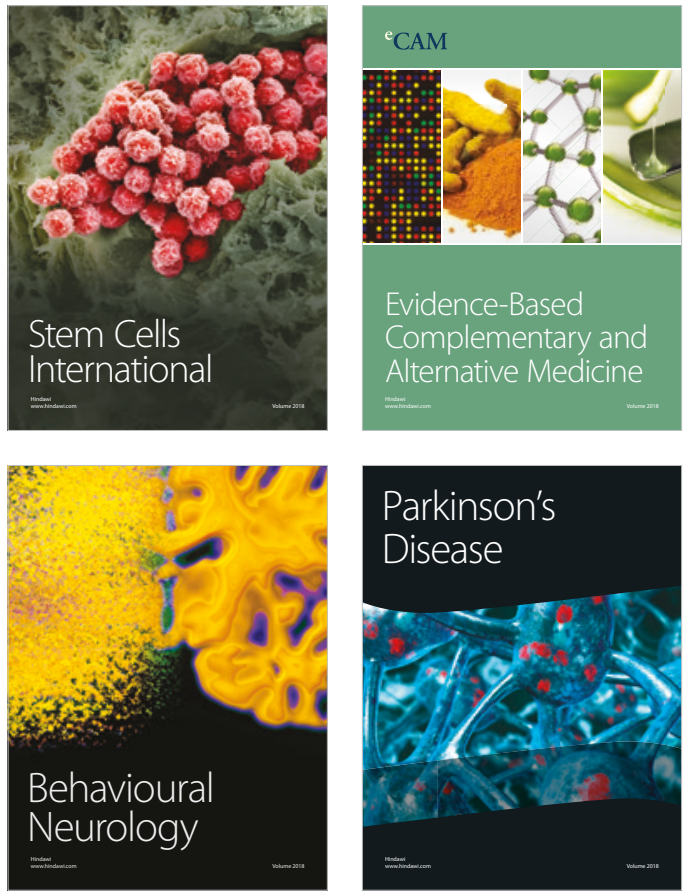

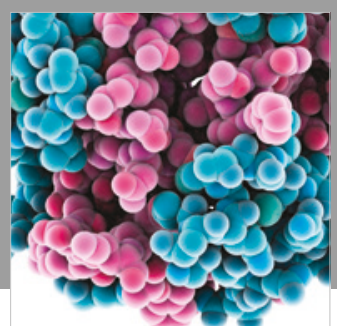

ournal of

Diabetes Research

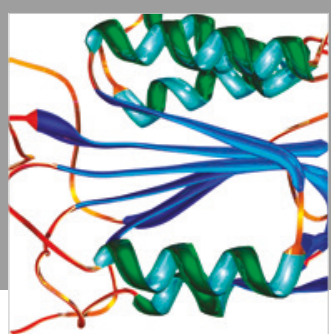

Disease Markers
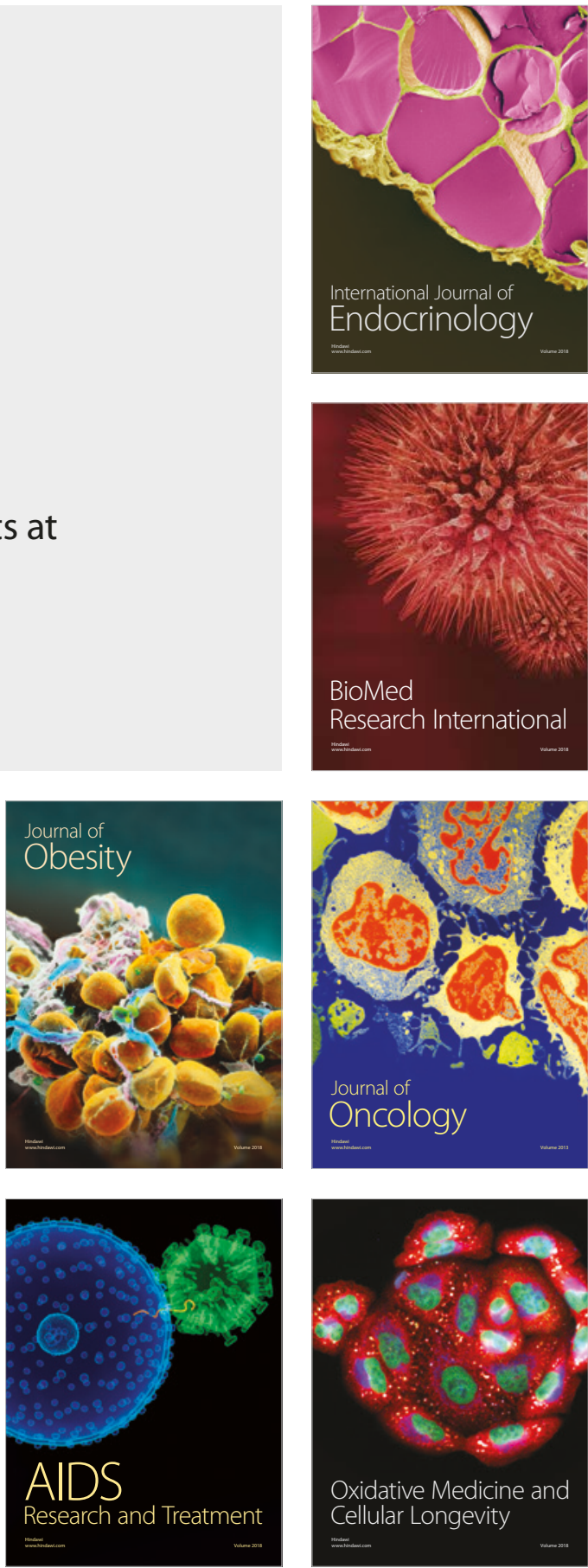